\title{
Evaluating hotel feasibility studies: lender perspective
}

\section{A.J. Singh* and Raymond S. Schmidgall}

The School of Hospitality Business, 232 Eppley Center, Michigan State University, East Lansing, MI 48824, USA

E-mail: singharj@msu.edu

E-mail: schmidga@msu.edu

*Corresponding author

\section{James W. Damitio}

Accounting,

Central Michigan University, Mount Pleasant, MI 48859, USA

E-mail: damit1j@cmich.edu

\begin{abstract}
Feasibility studies are prepared to receive financing for lodging properties. Financial lenders require a feasibility study from independent professional experts. This study explores the importance and satisfaction to the financial lenders of the various sections of a feasibility study. In general, financial lenders place considerable importance on these studies but are less satisfied with the results. The greatest differences between the degree of importance and the degree of satisfaction are noted for sections they consider most important. Based on an identification of gaps in the preparation of feasibility studies, the research proposes specific steps to make structural changes in the preparation of these studies. This research is a continuation of the issue raised in 1982 by Paul Beals and David A. Troy in their seminal paper titled 'Hotel feasibility analysis', which made some recommendations to improve feasibility studies. Since that time, there have been no major improvements in their preparation. This study begins by highlighting the specific shortcomings and attempts to begin a dialogue to establish minimum standards for the preparation of feasibility studies.
\end{abstract}

Keywords: feasibility studies; lodging market studies; lodging investments; market segmentation; lenders; satisfaction; importance; consultants.

Reference to this paper should be made as follows: Singh, A.J., Schmidgall, R.S. and Damitio, J.W. (2011) 'Evaluating hotel feasibility studies: lender perspective', Int. J. Built Environment and Asset Management, Vol. 1, No. 1, pp.74-93.

Biographical notes: A.J. Singh is the Associate Professor of International Lodging, Finance and Real Estate Finance in The School of Hospitality Business. He has recently co-authored three textbooks on International Hotel Management (2008), Hospitality Asset Management (2009) and Hotel Sustainable Development: Principles and Best Practices (2011). He has conducted several real estate market and feasibility studies while working as a

Copyright (C) 2011 Inderscience Enterprises Ltd. 
Consultant for Laventhol \& Horwath. He is a current member of the International Society of Hospitality Consultants.

Raymond S. Schmidgall is the Hilton Hotels Professor of Hospitality Financial Management at Michigan State University and is the School's Accounting and Financial Management Expert. He has published several hospitality accounting and financial management textbooks and worked as an Auditor with Ernst \& Young.

James W. Damitio is a Professor in the Department of Accounting at Central Michigan University, where he is also the Director of the Perry Schools of Banking and Director of the Entrepreneurship Programme. He is the co-author of a Hospitality Financial Accounting and Accounting for Club Operations text.

\section{Introduction and context}

Lenders have a limited pool of capital and should consequently originate loans with the highest expected return at a given level of risk. The primary cause of the failure of a real estate project can be attributed to the lack of an effective feasibility study, unsound or weak management or poor market timing (Sorenson, 1990). Therefore, from a lender's perspective, there are three important reasons why they should influence the content, preparation and analysis presented in feasibility studies.

Firstly, despite recommendations by scholars, industry professionals and lenders to make hotel feasibility studies more effective, the essential form of the studies has remained unchanged for a long time. A ground-breaking study that critically evaluated lodging feasibility studies (Beals, 1990) stated,

"In terms of the development of the hotel feasibility report, the period from the industry upheaval of 1973-1974 to the present has seen little change. Formal feasibility reports continue to be commissioned for hotel projects, but the essential methodology of the analysis and the format for the presentation of the results of the analysis have not changed."

As consultant feedback based on the current research will show, this sentiment continues into the present.

Secondly, although the hotel industry has gone through several periods of overbuilding in the past, including the mid-1970s and late 1980s, the terrorist attacks in 2001 catastrophically affected demand and hotel performance. The current financial crisis which started in 2008 has resulted in many changes in the financial markets, including availability of credit for new hotel projects. At the same time, banks are significantly increasing their loan loss reserves as a result of audits done by bank examiners. Even though financial institutions do have capacity to lend, they are scrutinising proposed projects much more carefully.

To a greater or lesser degree, during each of these periods, lenders were plagued with defaulted hotel loans and, in many cases, were unintended owners of hotel real estate, which are illiquid and management intensive in nature. Given the low margin (estimated at $2 \%$ return on assets) and high volume nature of commercial bank loans, each $\$ 1,000,000$ of lost principal requires that banks originate $\$ 50,000,000$ in new loans to 
compensate the loss $(\$ 1,000,000 / 2.0 \%=\$ 50,000,000)$. Lenders have a fiscal responsibility to their investors and depositors to reduce risk by exerting their influence on the preparation of feasibility studies (Roginsky, 2003).

Finally, as capital and management intensive projects, hotels are operating businesses 'housed' in real estate. Based on the Hospitality Valuation Services (Hotel Development Cost Survey), a hotel investment can cost anywhere between $\$ 70,000$ and over $\$ 700,000$ per room in today's environment (HVS, 2008). Compared to traditional commercial real estate classes (office, multi-family and industrial), hotels are a complex product with a range of product types from budget to full service, short-term leases with higher exposure to market vicissitudes, complex operating structures which may include owners, management companies and franchisers and only limited ability to 'pre-lease' the hotel rooms. These characteristics of hotel loans make them an inherently riskier asset class. With loan to values ranging from $55 \%$ to $70 \%$ for hotel projects, lenders have the largest proportion of capital at risk of all the parties involved in the project. While imposing restrictive lending terms may compensate for this exposure, a lender specified feasibility study will strengthen overall underwriting quality and protect the lender's interest.

\section{The purpose statement and research questions}

The purpose of this study was to survey large and small bank lending officers to identify the sections of a feasibility study they considered important and their satisfaction with the usefulness and reliability of the sections as currently prepared by consultants.

\subsection{Primary research questions}

1 What are the most important sections in a feasibility study for lending decisions? Are lenders satisfied with usefulness and reliability of these sections in a study as currently prepared by consultants?

2 Are there differences between large and small lenders in what is considered important in a feasibility study?

3 Are there differences between large and small lenders in their satisfaction with sections of a feasibility study?

\subsection{Secondary questions}

1 What are the most important factors influencing hotel loan decisions?

2 What are the most important criteria for recommending a feasibility consultant?

\section{Significance of the study}

Given the nature of the hotel investment, which is costly, highly leveraged, complex to operate and prone to financial distress as a result of overbuilding, the role of a welldesigned feasibility study provides a better assurance of predicting adequate return on investment. Over the years, feasibility studies have received their fair share of criticism as being ineffective in predicting future operating results of proposed hotel projects. As a 
result, many hotel and lodging owners, who purchase and commission these studies, view them as 'necessary evils' needed to secure financing. In order for lodging feasibility studies to evolve from merely serving as a financing document checklist to a valuable investment decision-making tool, it is important to start by investigating the relevance of feasibility studies as they are currently prepared based on a lender's perspective. Furthermore, this study serves to fill the lacunae in the academic literature on critiquing and analysing the feasibility study methodology. The topic is also timely; as in the aftermath of the recent financial crisis, lenders are expected to scrutinise proposed projects much more closely.

\section{Review of literature}

\subsection{Feasibility study definition and evolution of lodging feasibility studies}

One of the earliest definitions of a feasibility study was coined by James A. Graaskamp, Chairman of Department of Real Estate at the University of Wisconsin, where he pioneered a graduate programme considered by many as the 'West Point of Real Estate' (Jarchow, 1991). Based on his definition,

"A real estate project is feasible when the real estate analyst determines that there is a reasonable likelihood of satisfying explicit objectives when a selected course of action is tested for fit to a context of specific constraints and limited resources" (Graaskamp, 1970).

The current model of feasibility studies for the lodging industry was originally designed for the real estate industry, and later adapted for hotel use in the 1970s and 1980s as a response to developer attitudes (Beals, 1994). The original feasibility hotel models were designed by public accounting firms such as Pannell Kerr Forster and Laventhol \& Horwath. They designed the analysis using their experience in accounting and other commercial real estate such as office buildings and shopping centres. This method was formalised by Stephen Rushmore in his first book titled Hotels, Motels and Restaurants: Valuations and Market Studies (Rushmore, 1983). This model of market analysis asks whether demand exists for additional rooms in the subject market area. The model then goes on to estimate the rate of absorption of the proposed hotel (occupancy) at a stated price (average room rate). Finally, it estimates the income stream from the project for five years in the future. This is the most commonly used model and format practiced in the industry today.

The consulting firms preparing these studies utilised current and historical secondary data with no emphasis on primary marketing research. As a result, this method of market analysis, which is 'inferring demand for the subject property by inventorying existing demands', may be inadequate for the changing hotel development environment (Beals, 1994). In particular, there were three factors which differentiated the dynamics of the hotel development environment in the post-1960s period. They are as follows:

1 Hotels ceased being homogeneous products. This started with the introduction of motels in the era after World War II, which differentiated motels from hotels. Next, the concept of 'market segmentation' was introduced during this period, and a second generation of hotels, such as Marriott, Hyatt, Radisson and Ramada, were introduced. They attempted to penetrate markets using a segmentation strategy. The 
segmentation process reached its pinnacle in the 1980s. The late 1980s also saw the growth of 'product segmentation'. This was the result of the market segmentation concept of the 1960s (Singh, 1998).

2 As a result of market segmentation, the concept of franchising became popular as a mechanism for growth of the industry. The process became a self-perpetuating cycle as market segmentation led to the growth of franchises, and the franchises, to maintain their growth levels, created more products. The maintenance of a certain critical mass was important to drive profitability and franchise brand awareness. The franchise component of the US hotel industry was over 70\% (Kent and Hackel, 2009) with over 300 brands.

3 The third element that influenced industry dynamics starting in the 1970s was the introduction of the management contract. This was partially a result of the segmentation that was taking place in the industry, which further increased the complexity of hotel operations due to heightened competition (Rushmore, 1992).

In this type of development environment, economic and demographic trends, which influenced supply and demand for hotel rooms, were not the only influences on hotel development, but also the supplemental factors, such as chain presence strategy, development of critical mass by franchisers and a continuous evaluation of consumer needs by chains, to create new niches and penetrate an already over fragmented market, were important influences as well. Due to these changes in the development environment, future projections of performance have become much more difficult to predict with consequent implications for preparers of feasibility studies.

\subsection{Literature on feasibility study critique}

The seminal work on the critique of feasibility studies and proposed improvements was published in a two-part article in the Cornell Hotel and Restaurant Administration Quarterly in 1982. The studies identified specific deficiencies in the methodology of these studies and recommended ways in which the studies could be improved (Beals and Troy, 1982). Building on the initial research, in 1990, Paul Beals published the first systematic evaluation and critique of feasibility studies as part of his dissertation titled 'A critical evaluation of lodging industry feasibility reports' (Beals, 1990). The research identified several shortcomings of feasibility studies, such as disconnect between drivers of demand and demand, inadequate market segmentation, growth projections are subjective, the recommended facilities section is vague and financial feasibility is inadequately addressed in the studies (Beals, 1990). Using the interview technique, the study identified methods to improve the feasibility studies. Two of the major recommendations set forth by the research were that lenders should commission and pay for feasibility studies and consultants preparing feasibility studies should be better qualified (Beals, 1990).

Subsequent to this initial study, the literature has had several commentaries on the inability of feasibility studies to estimate future performance, critiques of studies and those who prepare them.

The purpose of a market study is to outline the determinants of demand and, based upon that, make an estimate of demand for a market area. Once the components of demand have been forecasted according to the analyst's needs, the next step is to 
compare these projections to the existing supply and proposed additions to the supply. "In effect, then market analysis is concerned with the existing economic health of a specific market area (city, region, etc.), its future, and the potential for new spatial units within that area" (Messener et al., 1977).

In 1985, the American Hotel \& Motel Association did a survey of user attitudes towards feasibility studies, and all surveyed maintained that the general market section of the report, which identifies broad economic and demographic trends for a given market, had very limited application to projecting demand (AH\&MA, 1989).

Another critique related to current methodology concerns how analysts estimate the supply of hotel rooms in their market analysis model. The analyst starts with the current supply of competitive hotels and adds a certain number of rooms, based upon projects expected to enter the market area. However, what about the period after that? When estimating demand, the analyst applies growth factors to the entire period of the study, based upon historic trends and related assumptions. This increases the demand for the market for the entire period of the study. However, in the case of supply, no such assumption is made. As a result, the study disproportionately increases demand, while it increases supply only for a limited period. The result is a higher market area occupancy estimate (Mosser, 1982).

A study comparing the performance projections in feasibility studies with actual performance identified several discrepancies between forecasted and actual results (Tarras, 1990).

A few papers in the 1980s and 1990s focused on the role of the consultant in the effectiveness of feasibility studies. Experts have stated that only if competent individuals provide potential lenders with accurate information, only then will these studies be an important part of the loan documentation package for lenders (Beals, 1994). It has also been pointed out that the qualifications and expertise of the individuals performing the study should be scrutinised carefully well before the study commences (Eckenstahler, 1994). In reality, many consulting firms that perform these studies have in the past turned the field work for the study over to their least experienced employees (Beals and Troy, 1982). The average hotel project is a very unique real estate deal and requires the preparer of the study to be more than just a real estate generalist (Butler and Benudiz, 1994).

As the hotel industry recovered in 1993 from cyclical overbuilding (and consequent hotel defaults) in the early 1990s, a series of industry articles, which were critical of feasibility studies, and counter articles by consultants were published defending their practice. A 1994 article by Beals observed that the problem with feasibility studies is related to its perception of being a 'necessary evil'. A developer could do without it, and a consultant was left with selling 'a product that my customers do not want'. The result was the preparation of a report at the lowest possible price with least methodological sophistication (Beals, 1994). Stanley Turkel, an industry observer and consultant, identified eight shortcomings in a feasibility study, including that most tend to be 'cookie cutter' products (Turkel, 1995). Robert C. Lewis, in a follow-up article, supported Turkel and added that consultants rarely publish a negative study, as they are paid by the developer and have a built-in bias (Lewis, 1996). Stephen Brenner, a consultant, noted in an article that the problem is not with the feasibility study but their interpretation. Many users of feasibility studies, according to him, do not understand the limitations of the projections (Taninecz, 1990). Two subsequent interpretative articles were written from the user perspective to help them interpret studies more realistically (Rushmore, 1996; 
Singh and Schmidgall, 1997). In general, the literature during this period reflected an attitude of 'looking for someone to blame'.

For the past ten years, the literature has been relatively silent about the topic of hotel feasibility studies, despite two cyclical downturns during that period, 2002 and the current cycle. In an article written by Rushmore in 2000, he continued to raise the question of feasibility study methodology. He said, "Unfortunately for the lodging industry, hotel market studies have not progressed far in sophistication. In fact some consultants are performing incorrect calculations that tend to skew their final projection of occupancy" (Rushmore, 2000). A recent study has shown that community bankers place more importance on their own internal financial projections than they do on the financial projections presented by the preparer of the formal hotel feasibility study (Singh et al., 2004).

The literature reviewed defined feasibility studies, reviewed the genesis of these studies and reasons why the studies needed to change. Several articles identified the specific shortcomings in feasibility studies and general recommendations for changing the methodology. A large gap in the literature currently exists on the relevance of feasibility studies which this research seeks to address.

\section{Methodology}

This research was based on a survey using a judgement sample consisting of large bankers (over \$2 billion in assets) and small bankers (under \$2 billion in assets), who were members of the Risk Management Association. Given the size differences, lending and risk profile of the loans, there could be a difference in perception between the two institutions on feasibility studies.

\subsection{Large bankers}

Thirty-four large bankers participated in the survey, with almost one-third of the respondents indicating that their bank was best described as a regional bank, while about $20 \%$ indicated their bank to be a community bank. The remaining respondents indicated that their banks were best described by other names such an investment bank or a thrift institution. Institutions in the study ranged in size from $\$ 2$ billion to $\$ 600$ billion in book value of their assets with an average of just over $\$ 51$ billion. The average amount of total real estate loans in respondent's loan portfolios was almost $\$ 6$ billion with the range from a low of $\$ 20$ million to a high of $\$ 30$ billion. The average total hotel loans in a respondent's portfolio were about $\$ 882$ million with a range from $\$ 10$ million to $\$ 12$ billion. Just over $40 \%$ of the respondents reported that their institution's staff had at least one individual that specialised in hotel loans.

\subsection{Small bankers}

Twenty-six small bankers completed the questionnaires. As a group, they had commissioned and reviewed 100 hotel feasibility studies in the past three years with an approximate book value of $\$ 857$ million in hotel loans. The majority of lenders made loans for new construction (77\%), refinancing (61\%) and acquisition of existing hotels (54\%). These were primarily represented by loans to full service (62\% of the lenders) and 
limited service $(58 \%$ of the lenders) hotels in the three- and four-star categories. The majority of the borrowers were partnerships and private hotel companies.

\section{Structure of survey instrument}

The survey instrument was a self-administered and close-ended questionnaire with a combination of nominal, categorical and ordinal scale questions. Section 1 of the survey included general demographic questions like 'Is your financial institution best described as a regional bank, community bank or a mortgage bank?' Respondents were also asked to report the approximate book value of their institution's total assets, as well as the approximate book value of their real estate loans in general. In addition, respondents were asked to indicate the book value of the hotel loans in their institution's real estate portfolio and if their institution included any staff that specialised in the hotel industry.

Section 2 of the survey asked respondents to indicate the purposes for which they granted loans to the hotel industry (new construction, expansion, etc.). They were also asked to report the type of hotel (full service, luxury, etc.) to which they granted loans, the price categories of the borrowers (upscale, mid-scale, etc.) and the owner type (private, real estate investment trust, C-Corp, etc.) to which they granted loans. In addition, in this section, they were asked to rate the importance of a list of 15 factors influencing hotel loan decisions such as the financial strength of the applicant, location of the site or hotel, etc. For this portion of the study, a five-point Likert scale was used ranging from ' 1 ' denoting 'crucial' to ' 5 ' denoting 'unimportant'. Finally, in Section 2, they were asked to indicate on the same Likert scale the importance of a number of consultant recommendation criteria such as 'accuracy of previous feasibility study projections' and 'professional reputation of the firm'.

In Section 3 of the survey, respondents were asked to rate from 1 to 5 (the same scale used in Section 2 of this survey) the importance they placed on the typical items that would be found in the hotel feasibility studies that are presented to them. This included a list of the factors mentioned above under each of the following general categories: general market characteristics, project, site and neighbourhood analysis, supply and demand analysis, recommended facilities, occupancy and average daily rate (ADR) projections, and of course, financial projections.

Bankers were requested to provide input on their satisfaction with the presentation of the entire same general category items listed above by rating them on a Likert scale ranging from ' 1 ' denoting 'completely satisfied' to ' 5 ' denoting 'completely dissatisfied'.

\section{Results and discussion}

\subsection{Hotel lending criteria}

Banks, both large and small, have well-established guidelines for lending. This study asked respondents to rate the importance of 16 lending criteria that lenders would consider in a loan of this type. The mean values and the ranking of these criteria by both the large and small lenders are shown in Table 1. None of the criteria were rated unimportant by either the large or small lenders. In addition, in the case of 13 of the 
16 lending criteria, the large lenders rated the criteria more important than the small lenders; only in the case of 'financial projections based on feasibility study', 'financial strengths of applicant' and 'lending trend for specific property type' did the small lenders rate the criterion more important than the large lenders.

For the large lenders, the top three criteria were first, 'location of hotel', followed by 'experience in hotel development and management' and 'financial strength of applicant'. For the small lenders, 'financial strength of the applicant' was ranked first followed by 'location of hotel' and 'experience in hotel development and management'. Thus, the top three lending criteria were the same for both large and small lenders. It is interesting to note that in the case of both the large and small lenders, 'financial analysis based on internal analysis' was rated more important than 'financial projections based on the feasibility study'. In fact, 'financial projections based on the feasibility study' was ranked 14 out of 16 on the list by the large lenders.

Table 1 Banker hotel lending criteria

\begin{tabular}{|c|c|c|c|c|c|}
\hline \multirow[b]{2}{*}{ Lending criteria } & \multicolumn{2}{|c|}{ Large lenders } & \multicolumn{2}{|c|}{ Small lenders } & \multirow[b]{2}{*}{ Mean differences* } \\
\hline & Rank & Mean & Rank & Mean & \\
\hline Location of site or hotel & 1 & 1.44 & 2 & 1.55 & -0.11 \\
\hline $\begin{array}{l}\text { Experience in hotel development and } \\
\text { management }\end{array}$ & 2 & 1.55 & 3 & 1.90 & -0.35 \\
\hline Financial strength of applicant & 3 & 1.58 & 1 & 1.40 & +0.18 \\
\hline Economic climate: metropolitan area & 4 & 1.66 & 6 & 2.10 & -0.44 \\
\hline Fit of proposed project in the market & 5 & 1.67 & 4 & 2.00 & -0.33 \\
\hline Financial projections based on internal analysis & 6 & 1.77 & 5 & 2.05 & -0.28 \\
\hline Management affiliation & 7 & 1.84 & 8 & 2.43 & -0.59 \\
\hline Brand affiliation & 8 & 2.06 & 9 & 2.52 & -0.46 \\
\hline Performance of sponsors' other businesses & 8 & 2.06 & 13 & 2.84 & -0.78 \\
\hline Barriers to entry into the market area & 10 & 2.22 & 11 & 2.55 & -0.33 \\
\hline Financial institution's expertise & 11 & 2.37 & 9 & 2.52 & -0.15 \\
\hline Profitability of loan to your financial institution & 12 & 2.39 & 12 & 2.65 & -0.25 \\
\hline Economic climate: national & 13 & 2.58 & 16 & 3.30 & -0.42 \\
\hline Financial projections based on feasibility study & 14 & 2.87 & 7 & 2.29 & +0.58 \\
\hline Lending trend for specific property type & 15 & 3.00 & 14 & 2.95 & +0.05 \\
\hline $\begin{array}{l}\text { Favourability of hotel sector with financial } \\
\text { institutions }\end{array}$ & 16 & 3.20 & 15 & 3.29 & -0.09 \\
\hline
\end{tabular}

*Large lender mean minus small lender mean.

Note: Scale

$1=$ crucial.

$2=$ very important.

$3=$ important.

$4=$ somewhat important.

$5=$ unimportant. 
There were significant mean differences of 0.40 or more between the means for the large vs. the small lenders for six lending criteria: 'financial projections based on feasibility study', 'economic climate: metropolitan area', 'economic climate: national', 'management affiliation', 'brand affiliation' and 'performance of sponsor's other businesses'. In each of these six cases, the large lenders rated the criterion more important than did the small lender.

\subsection{Consultant recommendation criteria}

Although lenders do not rely exclusively on hotel feasibility studies in determining whether to grant loans, these studies should provide them with valuable information on the proposed property. The choice of a consultant by a lender to conduct such a study would typically involve the recommendation criteria listed in Table 2.

None of the ten criteria in Table 2 was rated unimportant or even somewhat important by either the large or the small lenders. The top two criteria in the case of both the large and the small lenders were 'experience of market analyst researching and writing the report' and 'local knowledge of market segment in subject market area', respectively.

Table 2 Consultant recommendation criteria

\begin{tabular}{|c|c|c|c|c|c|}
\hline \multirow[b]{2}{*}{ Recommendation criteria } & \multicolumn{2}{|c|}{ Large lenders } & \multicolumn{2}{|c|}{ Small lenders } & \multirow[b]{2}{*}{ Mean differences* } \\
\hline & Rank & Mean & Rank & Mean & \\
\hline $\begin{array}{l}\text { Experience of market analyst researching } \\
\text { and writing the report }\end{array}$ & 1 & 1.35 & 2 & 1.53 & -0.18 \\
\hline $\begin{array}{l}\text { Local knowledge of market segments in } \\
\text { subject market area }\end{array}$ & 2 & 1.38 & 1 & 1.47 & -0.09 \\
\hline $\begin{array}{l}\text { Integrity of senior management responsible } \\
\text { for engagement }\end{array}$ & 3 & 1.97 & 5 & 2.00 & -0.03 \\
\hline Professional reputation of the firm & 4 & 2.03 & 4 & 1.94 & +0.09 \\
\hline $\begin{array}{l}\text { Consistent and recognised methodology } \\
\text { used }\end{array}$ & 5 & 2.06 & 3 & 1.63 & +0.43 \\
\hline Timeliness of delivery of study & 6 & 2.37 & 8 & 2.68 & 0.29 \\
\hline $\begin{array}{l}\text { Experience of senior management } \\
\text { responsible for engagement }\end{array}$ & 7 & 2.39 & 6 & 2.32 & +0.07 \\
\hline $\begin{array}{l}\text { Recommendations of other financial } \\
\text { institutions }\end{array}$ & 8 & 2.72 & 7 & 2.63 & +0.09 \\
\hline Pricing and fees charged for study & 9 & 3.30 & 10 & 3.33 & -0.03 \\
\hline $\begin{array}{l}\text { Financing institution's professional } \\
\text { reputation with firm }\end{array}$ & 10 & 3.39 & 9 & 3.28 & +0.11 \\
\hline
\end{tabular}

*Large lender mean minus small lender mean.

Note: Scale

$1=$ crucial.

$2=$ very important.

$3=$ important.

$4=$ somewhat important.

$5=$ unimportant. 
In five of the ten criteria, the large lenders rated the criteria more importantly than did the small lenders, and in the other five, small lenders rated criteria more importantly than did large lenders. Although Table 2 reveals that there was fairly good agreement between the large and small lenders with regard to the ranking of these ten criteria, there was one significant difference of 0.40 or more between the mean values of the two groups. In the case of 'consistent and recognised methodology used', the small bankers rated this criterion significantly more important than did the large lenders.

The six major parts of the typical hotel feasibility study are discussed and the differences in importance vs. satisfaction between large and small lenders in terms of the various items that fall within those six major parts of the study are analysed.

\subsection{General market characteristics}

The general market characteristics for the proposed hotel are typically discussed in the first portion of the feasibility study. The factors below are commonly discussed in the feasibility report.

Major demand generators, tourism trends, seasonality of market demand, employment trends, demographic trends, office vacancy statistics, environmental concerns, labour force characteristics, airport statistics, highway traffic counts, income level, retail sales and eating and drinking place sales.

Across the 14 factors under general market characteristics, the average importance to large lenders of these factors was rated 2.28 (see Table 3) and 2.37 (see Table 4) to small lenders. Thus, the differences were relatively minor between large and small lenders. Their mean satisfaction scores were 3.06 for large lenders and 2.80 for small lenders. The differences between the importance and satisfaction scores were 0.78 for large lenders and 0.43 for small lenders. The average scores of small and large lenders were lower in importance than for satisfaction, suggesting these lenders are relatively less satisfied with the general market characteristics than the importance they attach to this area.

The most important general market characteristics for both the large and the small banks, albeit in slightly different order, were 'major demand generators', 'economic climate', 'seasonality of market demand' and 'tourism trends'. All four were rated 'very important' by both groups of lenders. 'Major demand generators' and 'economic climate' were ranked one and two, respectively, by the large lenders, while the small lenders ranked 'seasonality of market demand' as number one followed by 'major demand generators'. The differences in the mean responses for the four most important general market characteristics are shown in Table 5.

However, when lenders were asked about their satisfaction with the information provided to them with regard to the general market characteristics portion of the study, both large and small lenders were 'somewhat dissatisfied' with the information provided in the study. Table 6 shows the satisfaction to the top four factors measuring general market characteristics. Overall, the differences between large and small lenders were relatively minor. 
Table 3 Comparison of average scores of importance and satisfaction

\begin{tabular}{lcccc}
\hline \multicolumn{5}{c}{ Large lenders } \\
\hline Sections & Factors & Importance & Satisfaction & Difference* $^{*}$ \\
\hline Supply and demand analysis & 9 & 1.68 & 3.36 & -1.68 \\
Occupancy and room rate analysis & 8 & 1.78 & 3.54 & -1.76 \\
Project and site analysis & 6 & 1.84 & 2.90 & -1.06 \\
Financial projections & 11 & 2.04 & 3.52 & -1.48 \\
Neighbourhood analysis & 7 & 2.19 & 3.21 & -1.02 \\
General market characteristics & 14 & 2.28 & 3.06 & -0.78 \\
Recommended facilities & 5 & 2.73 & 3.22 & -0.49 \\
\hline
\end{tabular}

*Satisfaction score less importance score.

Note: Importance scale

$1=$ crucial.

$2=$ very important.

$3=$ important.

$4=$ somewhat important.

$5=$ unimportant.

Satisfaction scale

$1=$ completely satisfied.

$2=$ mostly satisfied.

$3=$ somewhat dissatisfied.

$4=$ mostly dissatisfied.

$5=$ completely dissatisfied.

Table 4 Comparison of average scores of importance and satisfaction

\begin{tabular}{lcccc}
\hline \multicolumn{5}{c}{ Small lenders } \\
\hline Sections & Factors & Importance & Satisfaction & Difference* $^{*}$ \\
\hline Occupancy and room rate analysis & 8 & 1.61 & 2.93 & -1.32 \\
Financial projections & 11 & 1.79 & 2.75 & -0.96 \\
Supply and demand analysis & 9 & 1.83 & 2.53 & -0.70 \\
Project and site analysis & 6 & 2.02 & 2.98 & -0.96 \\
Recommended facilities & 5 & 2.18 & 3.05 & -0.87 \\
General market characteristics & 14 & 2.37 & 2.80 & -0.43 \\
Neighbourhood analysis & 7 & 2.59 & 3.00 & -0.41 \\
\hline
\end{tabular}

*Satisfaction score less importance score.

Note: Importance scale

$1=$ crucial.

$2=$ very important.

$3=$ important.

$4=$ somewhat important.

5 = unimportant.

Satisfaction scale

$1=$ completely satisfied.

$2=$ mostly satisfied.

$3=$ somewhat dissatisfied.

$4=$ mostly dissatisfied.

$5=$ completely dissatisfied. 
Table 5 Top four criteria revealing importance by major sections of hotel feasibility studies

\begin{tabular}{|c|c|c|c|}
\hline & Large lenders & Small lenders & Mean difference* \\
\hline \multicolumn{4}{|l|}{ General market characteristics } \\
\hline Major demand generators & 1.39 & 1.94 & -0.55 \\
\hline Economic climate & 1.63 & 2.06 & -0.43 \\
\hline Seasonality of market area demand & 1.77 & 1.87 & -0.10 \\
\hline Tourism trends & 2.07 & 2.00 & +0.07 \\
\hline \multicolumn{4}{|l|}{ Project and site analysis } \\
\hline Proximity of site to demand generators & 1.42 & 1.60 & -0.18 \\
\hline Site accessibility & 1.61 & 1.75 & -0.14 \\
\hline Site visibility & 1.68 & 1.75 & -0.07 \\
\hline Physical suitability & 1.90 & 1.87 & +0.03 \\
\hline \multicolumn{4}{|l|}{ Neighbourhood analysis } \\
\hline Construction and new developments & 1.75 & 2.41 & -0.66 \\
\hline Future expected changes in land use & 1.94 & 2.41 & -0.47 \\
\hline Review of land use & 2.16 & 2.50 & -0.34 \\
\hline Description of buildings & 2.19 & 2.53 & -0.34 \\
\hline \multicolumn{4}{|l|}{ Supply and demand analysis } \\
\hline Analysis of competitive supply & 1.43 & 1.39 & +0.04 \\
\hline $\begin{array}{l}\text { Analysis of historical occupancy by market } \\
\text { segment }\end{array}$ & 1.56 & 1.76 & -0.20 \\
\hline Identification of competitive supply & 1.59 & 1.47 & +0.12 \\
\hline Projected growth of total market demand & 1.63 & 2.00 & -0.37 \\
\hline \multicolumn{4}{|l|}{ Recommended facilities } \\
\hline $\begin{array}{l}\text { Meeting rooms and other facilities } \\
\text { recommended }\end{array}$ & 2.62 & 1.93 & +0.69 \\
\hline Guest room recommendation & 2.69 & 1.92 & +0.78 \\
\hline Concept recommendation & 2.73 & 2.50 & +0.23 \\
\hline $\begin{array}{l}\text { Food \& beverage }(\mathrm{F} \& \mathrm{~B}) \text { facilities } \\
\text { recommendation }\end{array}$ & 2.76 & 2.15 & +0.61 \\
\hline \multicolumn{4}{|l|}{ Occupancy and room rate projections } \\
\hline Sensitivity analysis (room rate projection) & 1.56 & 1.39 & +0.17 \\
\hline Sensitivity analysis (occupancy projection) & 1.59 & 1.61 & -0.02 \\
\hline Projected stabilised ADR & 1.63 & 1.29 & +0.34 \\
\hline Projected and stabilised occupancy percent & 1.63 & 1.33 & +0.30 \\
\hline \multicolumn{4}{|l|}{ Financial projections } \\
\hline Total revenue & 1.65 & 2.19 & -0.54 \\
\hline Sensitivity analysis & 1.78 & 1.60 & +0.18 \\
\hline Net income & 1.81 & 1.69 & +0.12 \\
\hline Revenue and expense projection bases & 2.00 & 1.67 & +0.33 \\
\hline
\end{tabular}

*Large lender mean minus small lender mean.

Note: Importance scale

$1=$ crucial.

$2=$ very important.

$3=$ important.

4 = somewhat important.

$5=$ unimportant. 
Table 6 Top four criteria revealing satisfaction by major sections of hotel feasibility studies

\begin{tabular}{|c|c|c|c|}
\hline & Large lenders & Small lenders & Mean difference* \\
\hline \multicolumn{4}{|l|}{ General market characteristics } \\
\hline Major demand generators & 3.11 & 3.00 & +0.11 \\
\hline Tourism trends & 2.95 & 2.85 & +0.10 \\
\hline Seasonality of market area demand & 2.89 & 3.23 & -0.34 \\
\hline Economic climate & 3.00 & 3.00 & 0 \\
\hline \multicolumn{4}{|l|}{ Project and site analysis } \\
\hline Proximity of site to demand generators & 2.95 & 2.81 & +0.14 \\
\hline Site accessibility & 2.84 & 2.73 & +0.11 \\
\hline Site visibility & 2.95 & 2.83 & +0.12 \\
\hline Physical suitability & 2.78 & 3.00 & -0.22 \\
\hline \multicolumn{4}{|l|}{ Neighbourhood analysis } \\
\hline Construction and new developments & 3.32 & 3.00 & +0.32 \\
\hline Future expected changes in land use & 3.26 & 2.85 & +0.40 \\
\hline Review of land use & 3.16 & 3.33 & -0.17 \\
\hline Description of buildings & 2.74 & 2.96 & -0.22 \\
\hline \multicolumn{4}{|l|}{ Supply and demand analysis } \\
\hline Analysis of competitive supply & 3.20 & 2.50 & +0.70 \\
\hline $\begin{array}{l}\text { Analysis of historic occupancy by market } \\
\text { segment }\end{array}$ & 3.40 & 2.50 & +0.90 \\
\hline Identification of competitive supply & 3.27 & 2.50 & +0.77 \\
\hline Projected growth of total market demand & 3.53 & 2.50 & +1.03 \\
\hline \multicolumn{4}{|l|}{ Recommended facilities } \\
\hline $\begin{array}{l}\text { Meeting rooms and other facilities } \\
\text { recommended }\end{array}$ & 3.31 & 2.88 & +0.43 \\
\hline Guest room recommendation & 3.23 & 2.75 & +0.48 \\
\hline Concept recommendation & 3.15 & 3.25 & -0.10 \\
\hline F\&B facilities recommendation & 3.38 & 3.25 & +0.13 \\
\hline \multicolumn{4}{|l|}{ Occupancy and room rate projections } \\
\hline Sensitivity analysis (room rate projection) & 3.71 & 2.44 & +1.26 \\
\hline Sensitivity analysis (occupancy projection) & 3.80 & 2.67 & +1.13 \\
\hline Projected and stabilised average room rate & 3.53 & 2.89 & +0.64 \\
\hline $\begin{array}{l}\text { Projected and stabilised annual hotel } \\
\text { occupancy }\end{array}$ & 3.33 & 2.90 & +0.43 \\
\hline \multicolumn{4}{|l|}{ Financial projections } \\
\hline Total revenue & 3.53 & 3.00 & +0.53 \\
\hline Sensitivity analysis & 4.00 & 2.60 & +1.40 \\
\hline Net income & 3.57 & 2.89 & +0.68 \\
\hline Revenue and expense projection bases & 3.33 & 2.44 & +0.89 \\
\hline
\end{tabular}

*Large lender mean minus small lender mean.

Note: Satisfaction scale

$1=$ completely satisfied.

$2=$ mostly satisfied.

3 = somewhat dissatisfied.

$4=$ mostly dissatisfied.

$5=$ completely dissatisfied. 


\subsection{Project and site analysis}

After discussing the general market characteristics, the feasibility study typically moves to a discussion of the specific items that are important to the lender. Project and site analysis involves the following items: physical suitability, site accessibility, site visibility, utilities or other infrastructure services, zoning laws or permits or restrictions and proximity of site to demand generators.

The average scores for large and small lenders across these six factors for both importance and satisfaction are shown in Tables 3 and 4 . For large lenders, the average importance score is 1.84 compared to 2.02 for small lenders. For large lenders, the average satisfaction score is 2.90 compared to 2.98 for small lenders. Once again, the satisfaction score lags the importance score but by a greater degree for large lenders than small lenders.

Both large and small lenders rated virtually all of the six factors for project and site analysis as very important to them in their lending deliberations. Large and small lenders ranked 'proximity of site to demand generators' as number one, followed by 'site accessibility' and 'site visibility' as shown in Table 5.

Regrettably, both large and small bankers were somewhat dissatisfied with the data on the above items in the average hotel feasibility study. As shown in Table 6, large lenders expressed the least satisfaction with the data on 'proximity of site to demand generators' and 'site visibility', while small lenders reported the least satisfaction with 'physical suitability' and 'site visibility'. Overall, the differences in satisfaction of large and small lenders of the four factors related to project and site analysis were not significant.

\subsection{Neighbourhood analysis}

The next section of the feasibility study is the neighbourhood analysis which involves the following seven factors: construction and new developments, future expected changes in land use, review of land use, description of buildings, street characteristics, noise and liveability cues and review of boundaries.

As shown in Tables 3 and 4, large and small lenders rated the importance of these factors as 2.19 and 2.59, respectively. Clearly, the large lenders place more importance than do small lenders on neighbourhood analysis. The satisfaction with the neighbourhood analysis is 'somewhat dissatisfied' based on average scores for satisfaction of 3.21 and 3.00 for large and small lenders, respectively. Again, as revealed in other sections of the feasibility study, lenders are not satisfied with this portion of the study.

Table 5 reveals the importance of the top four factors comprising neighbourhood analysis. The level of importance based on average score by factor suggests large lenders place more importance on these factors than do small lenders. The order of the top four factors, starting with 'construction and new developments' and ending with 'description of buildings', are the same for the two groups of lenders. Table 6 reveals the satisfaction scores for four factors under neighbourhood analysis. The differences go in both directions; i.e. for two factors, small lenders are less dissatisfied than large lenders, and for the other two factors the reverse is true. For both groups, the average score equates to 'somewhat dissatisfied'. 


\subsection{Supply and demand analysis}

The supply and demand analysis section of the feasibility study is crucial since the data in this section drives both the occupancy and the room rate projections for the proposed property. Lenders were asked to rate the importance of and satisfaction with the following supply and demand criteria: identification of competitive supply, analysis of competitive supply, projected growth of competitive supply, identification of product mix, analysis of historic occupancy by market segment, analysis of seasonality of market segment demand, turn away demand, projected growth of total market demand and projected growth of total market demand by segment.

Based on the average scores of importance as shown in Table 3, the supply and demand analysis section is the most important section of the feasibility study to large lenders. The average score of 1.68 is the lowest for the seven sections, yet a satisfaction average score of 3.36 reveals a major gap of 1.68 between importance and satisfaction to large lenders.

Small lenders place relatively less importance on this section than large lenders as revealed by the average score for importance of 1.83 as shown in Table 4 . The satisfaction score for small lenders is 2.53 or a gap of 0.70 , which is considerably less than the 1.68 gap for large lenders. Based on the research results, small lenders view this as the third most important section of a feasibility study.

All of the criteria listed above were considered between 'crucial' and 'very important' to both large and small lenders, with both groups ranking 'analysis of competitive supply' as the number one criterion. Large bankers ranked 'analysis of historical occupancy by market segment' as number two followed by 'identification of competitive supply'. Small lenders, on the other hand, ranked 'identification of competitive supply' as number two followed by 'analysis of historic occupancy by market segment' as shown in Table 5 .

Although neither large nor small lenders expressed a high amount of satisfaction with any of the supply and demand criteria, small lenders (average satisfaction score $=2.53$ ) were overall more satisfied than the large lenders (average satisfaction score $=3.36$ ) with regard to the information on these lending criteria as shown in Tables 3 and 4. Large lenders, as shown in Table 6, were least satisfied with the information on 'projected growth of total market demand' and 'analysis of historical occupancy by market segment', while the small lender's satisfaction with four factors related to supply and demand analysis was in the middle of 'mostly satisfied' and 'somewhat dissatisfied'.

\subsection{Recommended facilities}

Both groups of bankers were asked to rank the importance of the following five facilities factors: design recommendation, concept recommendation, guest room recommendation, $F \& B$ facilities recommendation and meeting rooms or other facilities recommendation.

Large lenders place the least importance on this section of the feasibility study as shown in Table 3. The average importance score for the five factors is 2.73 , while the average satisfaction score is 3.22. The importance and satisfaction gap of 0.49 is the lowest of the seven sections for large lenders. 
On the other hand, small lenders place more importance on the recommended facilities section of the feasibility study as revealed by the average scores shown in Table 4. The difference between the satisfaction and importance average score is 0.78 ; thus, it is greater than for large lenders.

The importance scores from large and small lenders for the top four factors are shown in Table 5. Clearly, small lenders consider each of these four factors to be more important than do large lenders. The two most important factors are 'meeting rooms and other facilities recommended' and 'guest room recommendation'. Both large and small lenders were somewhat dissatisfied with each of the top four factors for recommended facilities as shown in Table 6. For the two most important factors, the large lenders were less satisfied than the small lenders.

\subsection{Occupancy and room rates}

The study next turns to the issues of occupancy and room rates since these are the basis of the revenue projections for the proposed entity.

Projection criteria that are addressed include sensitivity analysis (best case and worse case analysis room rate projections), sensitivity analysis (best case and worse case occupancy projections), projected and stabilised average room rate, projected and stabilised annual hotel occupancy, projected and stabilised annual seasonal occupancy, projected and stabilised seasonal average room rate, projected and stabilised room rates by market segment and projected and stabilised occupancy by market segments.

Large lenders, based on average scores shown in Table 3, rate the importance of this section of the feasibility study second to supply and demand analysis. The average score across the eight factors was 1.78; however, their satisfaction average score was 3.54 , resulting in the greatest importance and satisfaction gap of any sections. Large lenders are the least satisfied with the two sections of the hotel feasibility, and they considered to be most important as revealed by the 1.68 and 1.76 importance and satisfaction gaps for 'supply and demand analysis' and 'occupancy and room rate analysis'.

Small lenders also place considerable importance on this section as shown in Table 4. The average score for importance is 1.83 , while the average score for satisfaction is 2.53 , resulting in an importance and satisfaction gap of 0.70 . This is considerably lower than the gap for large lenders of 1.76 .

No doubt, because of their importance in projecting revenue, all of these criteria were rated between crucial and very important to both groups of lenders (Table 5). The large bankers ranked 'sensitivity analysis' (best case and worse case, room rate projections) as number one and 'sensitivity analysis' (best case and worse case, occupancy projections) as number two. Small bankers, on the other hand, indicated that the number one criterion was 'projected and stabilised average room rate' with 'projected and stabilised annual hotel occupancy' as number two.

Neither large nor small bankers were satisfied with the occupancy and room rate projections provided in the typical lodging feasibility study. Large bankers were least satisfied with the 'sensitivity analysis, best case and worse case' for both room rate and occupancy projections as shown in Table 6 . 


\subsection{Financial projections}

The occupancy and room rate projections from the previous section of the hotel feasibility study are the basis for the financial projections for the proposed property.

The financial criteria in the study include total revenue, departmental and undistributed operating expenses, fixed charges, income before fixed charges, net income, projection period, revenue and expense projection bases, inflation factor, sensitivity analysis, debt service coverage ratio and estimate of reserve for replacement.

The financial projections tell the story in numbers. The average score, based on feedback from large lenders, for importance across the 11 factors is 2.04 (very important). The average score for satisfaction was 3.52 , which is in the middle of 'somewhat dissatisfied' and 'mostly dissatisfied'. The importance and satisfaction gap as shown in Table 3 is 1.48 for large lenders.

The average scores of importance and satisfaction for small lenders are shown in Table 4. This section of the hotel feasibility study is second in importance to occupancy and room rate analysis. The average importance score for small lenders is 1.79 , while the satisfaction score is 2.75 , resulting in a gap of 0.96, a significant gap, yet it is considerably smaller than the importance and satisfaction gap of the large lenders discussed previously.

Not surprisingly, the top four factors as shown in Table 5 were rated between 'crucial' and 'very important' to both the large and small bankers. Large bankers ranked 'total revenue', 'sensitivity analysis' and 'net income' as the top three, respectively, while small bankers ranked 'sensitivity analysis' as the number one criterion of the four shown in Table 5.

Both large and small lenders' satisfaction attitudes towards the top four factors for the financial projections section ranged from 'somewhat dissatisfied' to 'mostly dissatisfied'. Large lenders ranked 'sensitivity analysis' as most dissatisfied as shown in Table 6. Clearly, the large lenders were more dissatisfied with the four factors shown in this table than the small lenders.

\subsection{Synthesis, implication of results and recommendations for industry}

Clearly, bankers, both large and small alike, consider the information in hotel feasibility studies to be important in the loan documentation process for hotel lending. This study also reveals that bankers are not satisfied with the information provided by the studies. In addition, there are some significant differences between the attitudes of large and small bankers towards these studies. Lenders are partly accountable for the deterioration of these studies for several reasons, including unrealistic or unclear expectations, low fees, a lack of understanding of the hospitality business and a lack of face-to-face interaction with consultants.

Therefore, it would appear that feasibility studies in their current form are nothing more than a necessary evil designed to show adequate support for a project to move forward. Furthermore, it is also no surprise that given the marginalisation of the feasibility study in the development process, the methodological improvements for feasibility studies have remained stagnant as noted in the consultant feedback. Hence, the reports in many cases have deteriorated into commodities vs. a true feasibility of the project. 
Over the years, several reports, studies, articles and discussions have focused on blaming either the consultant for giving their stamp of approval on hotel projects or lenders for releasing funds for projects that ultimately failed. Those who have been active in hotel real estate development recognise that development is a multifaceted enterprise with many parties involved, which include lenders, consultants, developers and management and franchise companies. In addition, the role of the government in terms of fiscal policies and regulations is a critical aspect to be considered as well. Furthermore, even after receiving approval, the future performance of a hotel will depend on several macroeconomic factors and quality of management. Therefore, it is virtually impossible for a feasibility study to make a perfect prediction on hotel performance.

While it is true that a feasibility study will never be $100 \%$ accurate due to many unknown variables, adding primary demand interviews, scenario planning, sensitivity analysis and conducting full feasibility studies are some of the improvement measures. However, the aim and hope of the authors of this research study is to open a door for a dialogue on ways to establish minimum standards for the feasibility report and set up a system to ensure that the preparers of the study follow the minimum guidelines for its preparation.

\subsection{Limitations and future research}

Our research was based on a judgement sample rather than a random sample of financial institutions. Sixty financial institution's executives participated in billions of dollars of hotel loans. Though the selection of bankers was not random, the hotel loan portfolios of the respondents were very extensive.

Future research should be conducted with consultants and others who prepare the hotel feasibility studies and/or users of these studies for making their real estate expansion decisions. The consultants preparing the studies could provide their perspectives for enhancing the studies. Users, like developers, using these studies to secure hotel financing could also reveal their degree of satisfaction with the studies and perhaps their willingness to have full feasibility studies prepared.

\section{References}

American Hotel \& Motel Association, Committee on Market Research and Feasibility Studies (1989) 'Feasibility study use', Lodging, Vol. 14, pp.5-6.

Beals, P. (1990) 'A critical evaluation of lodging industry feasibility reports', Doctoral Dissertation, Cornell University, Dissertation Abstracts International, DA1-A50/07, p.2134.

Beals, P. (1994) 'Rehabilitating hotel feasibility studies', Real Estate Review, Vol. 24, No. 1, pp.58-60.

Beals, P. and Troy, D.A. (1982) 'Hotel feasibility analysis', The Cornell Hotel and Restaurant Administration Quarterly, Vol. 23, No. 1, pp.11-17.

Butler, J.R. and Benudiz, P.P. (1994) 'Hotel lending in the 1990s: amateurs beware', The Cornell Hotel and Restaurant Administration Quarterly, Vol. 35, No. 6, p.39.

Eckenstahler, C.R. (1994) 'Generating effective market and feasibility studies from your real estate consultant', Economic Development Review, Vol. 2, No. 3, pp.80-82.

Graaskamp, J.A. (1970) 'A guide to feasibility analysis', in S.P. Jarchow (Ed.), Graaskamp on Real Estate. Washington DC: Urban Land Institute, pp.76-92. 
Hospitality Valuation Services (2008) Hotel Development Cost Survey. San Francisco: Elaine Sahlins.

Jarchow, S.P. (1991) 'In memoriam: James A. Graaskamp, 1933-1988', in S.P. Jarchow (Ed.), Graaskamp on Real Estate. Washington DC: Urban Land Institute, p.viii.

Kent, S. and Hackel, E. (2009) The Essentials of Lodging Investment. New York: Goldman Sachs Group, Inc.

Lewis, R.C. (1996) 'Forum on feasibility studies told it like it is', Hotel \& Motel Management, Vol. 211, No. 14, pp.20-23.

Messener, S.D., Trimble, H.G. and Ward, R.L. (1977) Analyzing Real Estate Opportunities. Market and Feasibility Studies. Chicago, IL: National Association of Realtors.

Mosser, F.W. (1982) 'Hotel feasibility studies a personal view', Lodging Hospitality, Vol. 78, No. 98 , pp.74-76.

Roginsky, R.J. (2003) 'Underwriting the investment', in L.E. Raleigh and R.J. Roginsky (Eds.), Hotel Investments: Issues and Perspectives. East Lansing: Educational Institute of the American Hotel and Lodging Association, pp.293-304.

Rushmore, S. (1983) Hotels, Motels and Restaurants: Valuations and Market Studies. Chicago: Appraisal Institute.

Rushmore, S. (1992) Hotels and Motels: A Guide to Market Analysis Investment Analysis and Valuations. Chicago: Appraisal Institute.

Rushmore, S. (1996) 'Feasibility studies: fact or fiction', Lodging Hospitality, Vol. 52, No. 10, p.14.

Rushmore, S (2000) 'Bringing market studies into the 21st century', Hotels, Vol. 34, No. 9, p.28.

Singh, A. (1998) 'A predictive study to determine the structure, capital needs and performance of the lodging industry and the role of financial institutions in providing capital: a historic review of the 20th century and Delphi study to predict the scenario in years 2000 and 2005', Doctoral Dissertation, Michigan State University, pp.86-92.

Singh, A.J. and Schmidgall, R.S. (1997) 'How to analyze a lodging feasibility study', $A A H O A$ Hospitality, Vol. 2, No. 10, pp.66-73.

Singh, A.J., Schmidgall, R.S. and Beals, P. (2004) 'A survey of community banker attitudes toward hotel feasibility studies', The RMA Journal, Vol. 86, No. 7, pp.54-61.

Sorenson, R.C. (1990) 'Why real estate projects fail', Journal of Commercial Bank Lending, Vol. 72, No. 8, pp.4-12.

Taninecz, G. (1990) 'Feasibility studies inaccurately perceived', Hotel \& Motel Management, pp. $42-48$.

Tarras, J. (1990) 'Accuracy of hotel feasibility projections', FIU Hospitality Review, Vol. 8, No. 1, pp.53-59.

Turkel, S. (1995) 'Little reality in typical feasibility study’, Hotel \& Motel Management, pp.68-70. 